\section{SANATORIUM TREATMENT.}

To the Eatitor of THE LANCET.

SIR,-I should like to add one or two remarks to your annotation in THE LANCET of Nov. 14th on Professor Bang's paper on sanatorium treatment. It is not always possible to classify pulmonary tuberculosis or the results of its cure under different stages of the disease. Patients do not generally present a clear-cut, a well-defined first, second, or third stage when they come for treatment. The first stage often merges into the second, the second into the third. Even the classification into early, moderately advanced, and advanced stages may prove incorrect or misleading, as what one physician would consider early, another would call moderately advanced, and so on. Patients have been sent to me as early cases when they were really incurable and had to be sent home after a few days. Nor can the results of sanatorium treatment be tabulated according to the number of lobes involved, as a patient with four lobes slightly affected would be likely to get well, while another with only two lobes seriously diseased might succumb. Besides, as Dr. E. E. Prest pointed out in your last issue, very few patients are admitted into the sanatorium really in the first stage in spite of the Notification Act. No two patients are alike in the condition of their disease or in the extent of their cure. So that the present method of classification of sanatorium results is open to many fallacies which are apt to vitiate statistical figures brought forward to prove the efficacy of the treatment. In giving my results of sanatorium treatment published in my book on "Pulmonary Tuberculosis," I adopted a more practical plan and classified according to whether the patients sufficiently improved to return to work or not.

I agree with Professor Bang when he says that the results of some early cases are disappointing, while some advanced cases astonish one by getting well. Though the reason for this is rather obscure in a small number of cases, it is not difficult to explain in many others. Patients in the first stage handicapped with poor resistance and vicious sur. roundings often do badly, whereas those in the second stage with plenty of reserve vital powers do well and keep well. Again, it frequently happens that some patients apparently slightly affected think that there is very little the matter with them and do not carry out the treatment earnestly, but at the very first sign of return of health leave the sanatorium and take to their old ways and unhygienic lives when they get home, with the result that many of them relapse. But others though in an advanced stage, having suffered, and realising that their future as bread-winners depends upon the restoration of their health, do everything possible to get well and persevere in the treatment till they succeed. Also, as Dr. Prest has shown, many mild cases which are treated at home in a half-hearted and inefficient way drift into a chronic state, and when they do enter a sanatorium afterwards as first-stage cases do not make a satisfactory progress. So that the results of sanatorium treatment have more to do with such factors as the patient's resisting power, his persererance, his means and his after-care, \&c., than merely with the first, second, or third stage of the disease. When these factors are ignored or not taken into calculation, one is liable to blame the sanatorium treatment unjustly for any of its failure.

I am, Sir, yours faithfully, Mendip Hills Sanatorium, Wells, Dec. 1st, 1914. C. MUTHU,

\section{COAGULOSE.}

To the Editor of THE LANCET.

SIR,-We observe that in some newspapers a statement appears regarding what is called a recent medical discovery by Professor Kocher, of Berne, who has introduced a substance called "coagulen," which coagulates the blood and instantly stops bleeding when applied to a wound internally or externally.

May we mention that the coagulating principle, or fibrin ferment, of the blood was isolated some years ago by a British scientist, Dr. G. H. A. Clowes, with whom was associated Dr. F. C. Busch, these two gentlemen working in the New York State Medical Research Laboratory, Buffalo. The preparation received the name of "coagulose," and it has been on the British market for more than a year. Immediately after war was declared Dr. Clowes, who happened to be in this country at the time, interviewed a number of medical men connected with the War Office, and he donated to the War Office a supply of coagulose, so that it might be employed in the hospitals where the wounded soldiers are being treated. We have reason to know that it is being used in some of these hospitals, and that it is producing excellent results.

While this does not in the least detract from the merit of Kocher's discovery, common fairness warrants us in asking you to make it quite clear that the announcement of this discovery was anticipated by at least three years by an English. man working in America.

We are, Sir, yours faithfully,

London, W., Nov. 26th, $1914 . \quad$ PARKE, DAVIS, AND Co.

** An annotation in THE LANCET of April 11th of this year entitled "A New Physiological Hæmostatic" may be consulted.-ED.L.

\section{THE NATIONAL INSURANCE ACT.}

\section{Medical Treatment of Insured Persons Calued} UP FOR SERVICE WITH HIS MaJesty's Forces.

THE Insurance Commissioners, in response to requests for information as to the medical treat. ment during the war of insured persons who belong to the Naval or Army Reserve, or to the Territorial Forces, or have enlisted in the New Army, hare issued a memorandum for the use of medical practitioners. This states that such persons generally are regarded as serving sailors or soldiers from the moment at which they are called up, or enlisted, and accepted for service until disembodiment or discharge. During this period they are not entitled to medical or sanatorium benefits under the National Insurance Acts, and accordingly no liability for their treatment rests on the panel practitioners by whom they have been accepted. The position of such persons is not affected by the fact that they may be permitted temporarily to continue to reside at home, even though they may be concurrently engaged in civil employment. An insured person who has been sent home owing to illness, or in consequence of having been wounded, must also be 